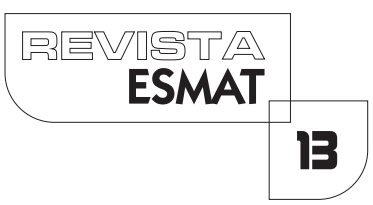

\title{
A CONSTRUÇÃO DE UMA SISTEMÁTICA PROTETIVA DA DIVERSIDADE: UM NOVO PASSO RUMO À PROTEÇÃO DOS DIREITOS HUMANOS
}

THE CONSTRUCTION OF A PROTETIVE SYSTEM IN ORDER TO PROTECT DIVERSITY: A NEW STEP REGARDING THE PROTECTION OF HUMAN RIGHTS

Fernando R. M. Bertoncello

Advogado. Formado em Direito pela Universidade Presbiteriana Mackenzie. Especialista em Direito Público e também em Direito e Processo Civil pela Universidade Cândido Mendes. Mestre e Doutorando em Direito Político e Econômico pela Universidade Presbiteriana Mackenzie, com período de pesquisa na University of Miami.

\section{RESUMO}

presente artigo procura demonstrar que os Direitos Humanos não foram meramente inseridos nos ordenamentos jurídicos, mas fruto de conquistas sociais históricas e de um processo evolutivo de uma compreensão sistemática do que são Direitos Humanos. Posteriormente, sugere-se que o próximo passo nesse processo evolutivo seja o desenho de uma sistemática protetiva da diversidade. Para a pesquisa, foi utilizada a metodologia qualitativa, calcada no método exploratório com base nas doutrinas e sites oficiais.

PALAVRAS-CHAVE: Direitos Humanos. Processo evolutivo. Sistemática de proteção dos direitos humanos.

\section{ABSTRACT}

This paper aims to demonstrate that human rights were not merely inserted into law, but they are a result of historical social achievements and also an evolutionary process of a systematic understanding regarding what human rights are. Afterwards, it is suggested that the next steps to be taken regarding the evolutionary process of human rights should be a system regarding the protection of diversity. For the research was a qualitative methodology had been used, based on an exploratory method and also based on doctrines and official websites.

KEYWORDS: Fundamental Human Rights. Evolutionary process. Systems to protect human rights. 


\section{INTRODUÇÃO}

$\bigcirc$ presente artigo procura demonstrar que tais direitos não foram meramente inseridos nos ordenamentos jurídicos, mas fruto de conquistas sociais históricas e de um processo evolutivo de uma compreensão sistemática do que são Direitos Humanos.

Sob uma perspectiva evolutiva de proteção dos Direitos Humanos, parece que a construção desta proteção passou da religião à filosofia, da formação de um sistema constitucional de proteção garantido pelos Estados a um sistema internacionalizado (em âmbito global e regional), garantido pela comunidade internacional, bem como por sistemas de integração regional e de livre-comércio.

Sendo assim, essa construção deu-se no sentido de reconhecer que tanto na ordem constitucional liberal quanto na ordem internacional regional parece haver um supraprincípio de proteção da diversidade humana implícito. Dessa forma, o presente artigo procura apontar que a construção de um subsistema de proteção (constitucional e internacional) da diversidade parece necessário; bem como se aprofundar no que consiste a efetiva proteção da diversidade.

Vale dizer que a presente proposta não se trata de um conceito fechado em si mesmo e que, para tanto, serão utilizadas outras disciplinas que tratem das temáticas abordadas sem, todavia, que se fuja da proposta de uma cidadania solidária que construa um Estado por meio do Direito.

Vale ressaltar que, exatamente por não se estar discutindo um conceito fechado, o presente artigo não tem a pretensão de sedimentar um conceito estático, mas sugerir propostas que começam a ser discutidas para que se possa avançar mais um passo no que diz respeito à proteção dos Direitos Humanos, a fim de contribuir para o fortalecimento dessa sistemática complexa que vem evoluindo.

A metodologia utilizada teve por base a pesquisa descritiva, qualitativa e exploratória, com uma análise interpretativa do tema baseado no levantamento bibliográfico por meio de doutrinas, da legislação nacional e internet, tendo por escopo a análise não somente da evolução, mas também da aplicação dos Direitos Humanos, estimulando assim o debate sobre quais os próximos passos a serem dados diante da postura dos Estados e da sociedade civil.

\section{OS PRIMEIROS PASSOS HISTÓRICO-FILOSÓFICOS PARA A CONSTRUÇÃO DO CONCEITO DE DIREITOS HUMANOS}

Sobre a origem dos direitos humanos e, sobretudo, no que diz respeito à sua compreensão, Donnely ( $198 \mid$ ) afirma que:

Enquanto a linguagem dos "direitos humanos" é um fenômeno do século $X X$, o conceito tem raízes profundas na tradição ocidental do pensamento político. Quão longe, porém, podemos rastrear essas raízes, e exatamente onde elas estão? 
Os "direitos naturais" e os "direitos do homem" estão claramente ligados ao conceito de direitos humanos (p. 36) (em tradução livre)! .

Sendo assim, percebe-se uma forte conexão entre a noção de Direitos Naturais e Direitos Humanos.

Vale lembrar que direito natural (ius naturale, no latim) ou jusnaturalismo é uma teoria que tem como projeto avaliar as opções humanas com o propósito de agir de modo razoável e bem, o que, por sua vez, é alcançado por meio da fundamentação de determinados princípios do Direito Natural, considerados bens humanos evidentes em simesmos (FINNIS, 2007).

A tutela dos bens humanos, objeto do Direito Natural, seria, portanto, a tutela daquilo que é inerente ao ser humano e constitui elemento essencial para sua construção enquanto tal, o que, claramente, confunde-se com o conceito de tutela dos Direitos Humanos.

Nesse sentido, Dalmo de Abreu Dallari (2000) afirma que,

No final da Idade Média, no século XIII, aparece a grande figura de Santo Tomás de Aquino, que, tomando a vontade de Deus como fundamento dos direitos humanos, condenou as violências e discriminações, dizendo que o ser humano tem direitos naturais que devem ser sempre respeitados, chegando a afirmar o direito de rebelião dos que forem submetidos a condições indignas (p. 52) (grifou-se).

A partir da segunda metade da Idade Média, começa-se a difundir documentos escritos, reconhecendo-se direitos a determinadas classes sociais, a determinadas comunidades, mas não ainda a todas as pessoas, não existindo nenhuma proposta de universalização (FERREIRA FILHO, 1998). Dentre estes documentos, merece destaque a Magna Carta, outorgada por João Sem-Terra, no século XII, em razão de pressões exercidas pelos barões, decorrentes do aumento fiscal para financiar campanhas bélicas e pressões da Igreja para o Rei submeter-se à autoridade papal (COMPARATO, 2003). Esse documento reconheceu vários direitos, como a liberdade eclesial, a não existência de impostos, sem anuências dos contribuintes, a propriedade privada, a liberdade de ir e vir e a desvinculação da lei e da jurisdição da pessoa do monarca (COMPARATO, 2003).

A Grécia Antiga, contudo, também foi importante para se chegar ao conceito de direitos humanos, uma vez que corroborou no sentido de colocar a pessoa humana

'While the language of "human rights" is a twentieth century phenomenon, the concept has deep roots in the Western tradition of political thought. How far back, though, can we trace these roots, and exactly where do they lie? "Natural rights" and "the rights of man" clearly are closely connected to the concept of human rights. 
como centro da questão filosófica. Ou seja, passou-se de uma explicação mitológica da realidade para uma explicação antropocentrista, possibilitando-se, então, refletir sobre a vida humana (MARTINS, 2003). Nesse mesmo sentido, houve grande contribuição da reforma protestante, que contestou a uniformidade da Igreja Católica e deu importância à interpretação pessoal das escrituras sagradas (LALAGUNA, 1993).

Alexandre de Moraes (2000), ao tratar da evolução histórica dos direitos fundamentais, verifica que o Código de Hammurabi pode ser o primeiro texto normativo codificado da história universal a consagrar uma série de direitos comuns, como a propriedade, a vida, a honra, a dignidade, a família; bem como a prever a supremacia das leis em face dos governantes.

A Torah, (ou Pentateuco ou Lei de Moisés), que ainda hoje constitui texto central do judaísmo, escrita por volta do século XII a.C (I300 a.C), traz um conjunto de regras religiosas, morais e sociais impostas obrigatoriamente ao povo de Israel (ARRUDA, 1995). Essa lei contemplava os dez mandamentos que são leis tidas como de inspiração divina. Nas palavras de Césare Cantu (2003):

\begin{abstract}
Como a primeira doutrina que Deus deu ao homem ao mesmo tempo em que a palavra que os patriarcas tinham transmitido, se tenha obscurecido, aprouve ao Senhor revelar novamente a sua vontade e das alturas do Sinai deu a Moisés o Decálogo, em que está resumido tudo quanto forma a moral do homem e a civilização dos povos. A unidade de Deus, proclamada à frente da lei, traz consigo a unidade da espécie e desde então começa a igualdade entre os homens: a mesma proibição dos maus pensamentos sanciona a individualidade, e faz que cada um se julgue e se reconheça um ente digno de respeito. Moisés teve de lutar contra a obstinação de um povo agreste e inculto, que enquanto seu profeta lhe preparava em dez linhas as regras da vida, sacrificava ao boi Ápis e respondia aos benefícios com murmúrios (p. 259) (grifou-se).
\end{abstract}

Ou seja, a própria formação judaico-cristã, sobretudo dos povos do ocidente, parece ter corroborado com o entendimento de que há direitos inerentes à natureza humana.

Nesse mesmo sentido, é importante lembrar que

[...] a lei da caridade universal é tão fundamental no conceito de Jesus Cristo, que a equipara à lei máxima do amor a Deus. Mais ainda, através da fraternidade universal, através das obras de amor ao próximo, deve-se realizar, segundo a vontade de Jesus Cristo, o amor a Deus, dependendo destas obras o destino eterno do ser humano. Tão universal e tão perfeita há de ser esta caridade, que ela inclua mesmo os inimigos, a exemplo do 
amor que neste mundo o próprio Deus tem para com os homens maus (SODER, 1960, p. 60).

Percebe-se, portanto, a contribuição da formação judaico-cristã na construção do que é ser humano e, sobretudo, na construção de quais são os seus direitos.

Acerca dessa contribuição, Pinsky (2003) afirma que, ao longo da história, formouse um monoteísmo ético. Trata-se de uma concepção revolucionária para a época do que é ser deus (ou, talvez, do que é ser humano, pois, a partir do momento em que se tem um deus ético, desenha-se um ser humano ético). Esse monoteísmo ético se transforma na base do judaísmo, do cristianismo e do islamismo. Ele estrutura um longo caminho (que não está terminado) do que são os direitos humanos.

Esse fundamento ético avança na história e, ao longo dela, reconhece-se a relevância das revoluções inglesa, americana e francesa para o reconhecimento de direitos inerentes à pessoa humana e suas respectivas influências nas constituições do século XIX(RUBIO, 1998).

A revolução inglesa (ocorrida entre 1640 e 1688) é considerada a primeira revolução burguesa da história. Ela representa: a transição de um capitalismo comercial para um capitalismo industrial; a formação de um novo modelo econômico; e também a formação de uma monarquia constitucional. Ou seja, um estado absolutista, gerido por monarcas, mas com dominação econômica de classes burguesas (SMANIO, 2009).

Para Smanio (2009), do ponto de vista social, a revolução inglesa passou a desenhar um estado pautado no modelo individualista hobbesiano, o que significa dizer que se encontrando num mundo hostil, tanto em face da natureza quanto em relação a seus semelhantes, o ser humano buscou reagir a essas hostilidades inventando técnicas de sobrevivência pelos sistemas de regras que reduzem os impulsos agressivos mediante penas, ou estimulam os impulsos de colaboração e de solidariedade por meio de prêmios (BOBBIO, 1992). Dessa forma, então, inaugura-se o liberalismo com a proteção dos direitos civis por meio de uma carta de direitos - a bill of rights (SMANIO, 2009).

A revolução americana, por sua vez, efetivada com a Declaração de Independência, de 1776, e também com a Constituição, de 1787, trata-se de outra revolução burguesa muito importante, uma vez que significa aprofundar-se no indivíduo e garantir a proteção econômica e privada deste (SMANIO, 2009).

Sobre a revolução americana, Bobbio (1992) entende que, além da proteção econômica e privada do indivíduo, ela teve como seu fundamento:

(...) ○ direito natural; idêntico era o desfecho, o governo fundado no contrato social, a república como governo que rechaça para sempre a lei da hereditariedade, a democracia como governo de todos (p. 36) (grifou-se).

Nesse mesmo sentido, Smanio (2009) aponta que a revolução francesa, a terceira 
revolução burguesa, é fundada na ideia de direitos naturais (liberdade, igualdade e fraternidade) e, por meio da Declaração de Direitos do Homem e do Cidadão, de 26 de agosto de 1789, dá uma dimensão jurídica e política à cidadania liberal.

\section{OS DIREITOS HUMANOS E A CONSTRUÇÃO DO CONSTITUCIONALISMO}

Posteriormente, outras constituições ${ }^{2}$ inspiraram-se nos modelos americano e francês, sobretudo no que diz respeito à garantia e defesa desses direitos naturais ao ser humano (DA SILVA, 20I6). Dessa forma, o desenvolvimento dos direitos humanos seguiu seu curso afirmando-se durante o constitucionalismo liberal do século XIX, adquirindo, a partir do século XX, característica de universalidade (DA SILVA, 20 | 6).

Percebe-se, portanto, que o século XVIII representou a conquista dos direitos civis (vida, liberdade, propriedade e igualdade perante a lei). $\bigcirc$ século XIX, por sua vez, representou a conquista dos direitos políticos, uma vez que a principal discussão versava sobre a participação popular no governo. Por fim, o século $X X$ representou as conquistas no âmbito dos direitos sociais (SMANIO, 2009).

Foi desse modo que o início do século $X X$ trouxe diplomas fortemente marcados pelas preocupações sociais. Nesse sentido, Vicente Bagnoli (2005) aponta para três documentos pautados nessas preocupações: a Constituição do México, de 1917; a Constituição de Weimar, de 19 | 8; e a Encíclica Rerum Novarum. ${ }^{3}$

A Constituição Mexicana é considerada marco normativo em matéria de direitos humanos porque garantiu direitos individuais com fortes tendências sociais, sobretudo no campo trabalhista (artigo $5^{\circ}$ ) e no que diz respeito à efetivação da educação, artigo $3^{\circ}$, (DA SILVA, 2016).

Sobre a constituição de Weimar ${ }^{4}$, Gilberto Bercovici (2005) entende que ela dividese em três níveis:

primeiro nível seria o dos direitos fundamentais, sociais e

\footnotetext{
${ }^{2}$ Nesse sentido, vale citar o exemplo da Constituição Espanhola, de 19 de março de 1812 (Constitución de Cádiz), popularmente conhecida como "La Pepa", que previa o princípio da legalidade, restrições aos poderes do rei, o princípio do juiz natural, a proibição de tributos arbitrários, o direito de propriedade, a desapropriação mediante justa indenização e a liberdade; bem como a Constituição Portuguesa, de 23 de setembro de 1822, que, por sua vez, consagrou direitos: à liberdade, à segurança, à propriedade, à inviolabilidade do domicilio, à igualdade perante a lei, à liberdade de expressão, à liberdade de imprensa, ao sigilo de correspondência, à educação e à assistência, à proibição da prisão sem culpa formada, à humanização do direito penal com a proibição de todas as penas cruéis (tortura) e/ou infamantes e à humanização do direito penitenciário (DA SILVA, 2016).

${ }^{3}$ Publicada pelo Papa Leão XIII, a encíclica trata da condição dos operários e propõe auxílio a estes homens.

${ }^{4}$ Sobre as origens históricas da Constituição de Weimar, Bagnoli (2005), aponta que: "antes mesmo da celebração do armistício da primeira guerra de II de novembro de 1918, a Alemanha
} 
econômicos, como o direito ao trabalho (art. 163), a proteção ao trabalho (art. 157), o direito à assistência social (art. | 61 ), e o direito de sindicalização (art. 159). Outro nível social seria o do controle da ordem econômica capitalista por meio da função social da propriedade (art. 153) e da possibilidade de socialização (art. 156). Finalmente, o terceiro nível seria o mecanismo de colaboração entre trabalhadores e empregados por meio de conselhos (art. 165). Com esta organização, a ordem econômica de Weimar tinha o claro propósito de buscar a transformação social, dando um papel central aos sindicatos para a execução desta tarefa (p. 18) (grifou-se).

\section{POR UMA PROTEÇÃO GLOBAL E REGIONAL EM MATÉRIA DE DIREITOS HUMANOS}

A Segunda Guerra Mundial, considerada a guerra mais abrangente e mais letal da história humana, marcada por um número significante de ataques contra civis, incluindo o Holocausto e o uso de armas nucleares - com a série de atrocidades cometidas -, demonstrou que os direitos dos indivíduos enquanto seres humanos deveriam ser protegidos em escala global, por meio do direito internacional (DA SILVA, 20 I 6).

Com o fim da II Guerra Mundial e a derrota dos Estados totalitários nazifacistas, 5 I países reuniram-se em São Francisco, nos Estados Unidos da América, e firmaram a Carta fundadora das Nações Unidas ${ }^{5}$, em 26 de junho de 1945. Esta "Carta das Nações Unidas" espelha a preocupação com a internacionalização de direitos humanos desde seu preâmbulo.

Com o objetivo de desenvolver os princípios da Carta, foi constituída a comissão dos direitos humanos, cujos objetivos principais consistiam em preparar uma declaração universal relativa aos direitos civis, políticos, econômicos e sociais, bem como elaborar

foi palco de diversas disputas internas que culminaram na República de Weimar. Na noite de 7 de novembro, proclama-se na Baviera uma República Democrática e Socialista por meio dos partidos de esquerda mais radicais. Aos 9 de novembro, o partido socialista alemão proclama a República na chancelaria de Berlim. No final de 1918, já com uma nova lei eleitoral, realizam-se as eleições para formar o congresso dos representantes das províncias imperiais, que, eleito, vota em janeiro de 1919 pela convocação da Assembleia Nacional Constituinte" (p.37).

${ }^{5}$ A Liga das Nações foi substituída pela Organização das Nações Unidas neste contexto pósSegunda Guerra. Vale lembrar que, embora não tivesse a mesma pretensão de internacionalização de direitos inerentes ao ser humano, já apresentava preocupações relativas a causas, como a escravidão, mulheres envolvidas em prostituição, direitos dos trabalhadores e a proteção de algumas minorias (CLAPHAM, 2007, p. 28). 
um documento juridicamente mais vinculante do que uma mera declaração, na forma de tratado, pacto ou convenção, redigido em termos legais, relativo aos direitos civis e políticos, de cumprimento obrigatório para todos os Estados que o assinasse e ratificasse e, por fim, propor medidas para programar os princípios da declaração e os dispositivos da convenção para examinar as petições e as reclamações de indivíduos ou grupos (DA SILVA, 2016).

Sendo assim, a Assembleia Geral da ONU, reunida em Paris, adotou a Declaração Universal do Homem e do Cidadão (atualmente, reconhecida como Declaração Universal de Direitos Humanos ${ }^{6}$ ).

Sobre a Declaração Universal de Direitos Humanos, Bobbio ( 1992 ) afirma que,

Com a Declaração de 1948, tem início uma terceira e última fase, na qual a afirmação dos direitos é, ao mesmo tempo, universal e positiva: universal no sentido de que os destinatários dos princípios nela contidos não são mais apenas os cidadãos deste ou daquele Estado, mas todos os homens; positiva no sentido de que põe em movimento um processo em cujo final os direitos do homem deverão ser não mais apenas proclamados ou apenas idealmente reconhecidos, porém efetivamente protegidos até mesmo contra o próprio Estado que os tenha violado (p. 18) (grifouse).

Percebe-se, portanto, uma forte revolução no que diz respeito à proteção dos direitos humanos, visto que ganham universalidade, o que significa dizer que qualquer ser humano deve possuir sua natureza humana preservada e protegida, até mesmo em relação ao seu próprio Estado da qual é nacional.

É bastante importante a quebra desse paradigma. Nesse sentido, até Hannah Arendt ( 1989) afirma que no mundo do século $X X$ perder a nacionalidade significava ser expulso da humanidade, pois direitos humanos nada valiam para aqueles que eram considerados apátridas ou os que tinham o azar de nascer em Estados que violassem seus direitos humanos mais essenciais às suas próprias existências.

Percebe-se também, ao longo desta narrativa sobre a evolução dos direitos humanos, o quanto evoluíram em termos conceituais: da conceituação tradicional de

\footnotetext{
${ }^{6}$ Sobre essa mudança de nomenclatura, embora os temas sejam mais discutidos à frente, é importante salientar que essas mudanças contemplam uma evolução, sobretudo na temática dos gêneros, visto que se faz necessário proteger os direitos de qualquer ser humano (independentemente de seus mais diversos gêneros) e, também, independentemente de serem considerados cidadãos, ou não, uma vez que o conceito de cidadão e nacional confunde-se e, dessa forma, a referida terminologia pode tornar-se excludente.
} 
direito natural desenvolvida por filósofos como São Tomás de Aquino, posteriormente evoluindo para sua emanação por meio de direitos positivos particulares, para finalmente encontrarem sua plena realização como direitos positivos universais.

Nesse mesmo sentido, Bobbio (1992) aponta que

A Declaração Universal contém em germe a síntese de um movimento dialético, que começa pela universalidade abstrata dos direitos naturais, transfigura-se na particularidade concreta dos direitos positivos, e termina na universalidade não mais abstrata, mas também ela concreta, dos direitos positivos universais (p. 18).

Além da Declaração Universal de Direitos Humanos, aprovaram-se dois pactos, um sobre direitos civis e políticos, e outro sobre direitos econômicos, sociais e culturais: o Pacto Internacional Relativo aos Direitos Econômicos, Sociais e Culturais, vigente desde 3 de janeiro de 1976 e o Pacto Internacional dos Direitos Civis e Políticos, vigente desde 23 de março de 1976.

Posteriormente, a comunidade internacional tem trabalhado na criação de mecanismos capazes de assegurar a observância universal desses direitos, por exemplo, a instituição de um processo de reclamações na Comissão de Direitos Humanos das Nações Unidas, objeto do Protocolo Facultativo relativo ao Pacto Internacional sobre os Direitos Civis e Políticos por parte dos Estados (CLAPHAM, 2007).

Em um âmbito mais específico, vale ressaltar também que foram editados diversos tratados internacionais ${ }^{7}$, a fim de proteger direitos específicos de determinadas minorias, as quais precisavam de ações afirmativas para poderem colocar-se perante suas respectivas sociedades.

Nesse sentido, portanto, Bobbio ( 1992) aponta:

(...) a passagem ocorreu do homem genérico — do homem enquanto homem - para o homem específico, ou tomado na diversidade de seus diversos status sociais, com base em diferentes critérios de diferenciação (o sexo, a idade, as condições físicas), cada um dos quais revela diferenças específicas, que não permitem igual tratamento e igual proteção. A mulher é diferente do homem; a criança, do adulto; o adulto, do velho; o sadio, do doente; o doente temporário, do doente crônico; o doente mental, dos outros doentes; os fisicamente normais, dos deficientes, etc. (p. 34) (grifou-se).

\footnotetext{
${ }^{7}$ Importante salientar que a terminologia tratado internacional utilizada aqui, bem como no decorrer desta tese, refere-se ao gênero que, à luz do direito internacional, pode compreender protocolos, convenções, declarações, tratados em sentidos estrito, bem como outros diplomas internacionalistas.
} 
Com este intuito de, de fato, observar as minorias e proteger a diversidade, esses tratados internacionais em âmbito específico foram editados, como, por exemplo: a Convenção sobre os Direitos Políticos da Mulher, em 1959; a Declaração da Criança, em 1971; a Declaração dos Direitos do Deficiente Mental, em 1975; a Declaração dos Direitos dos Deficientes Físicos, em 1982; dentre outros.

Mesmo com a proteção de direitos específicos, ainda se percebeu que muito precisaria ser feito em matéria de proteção dos direitos humanos e, assim, começaram a surgir sistemas regionalizados de proteção desses direitos. Dessa forma, surgiram: o Sistema Interamericano de Direitos Humanos ${ }^{8}$; o Sistema Africano de Direitos Humanos '; e o Sistema Europeu de Direitos Humanos ${ }^{10}$ (CLAPHAM, 2007).

Sobre o questionamento feito, vale lembrar as palavras de Eleonor Rossevelt (1958) quando proclamou a Declaração Universal de Direitos Humanos. Em tal Declaração, a relatora da Comissão procurou entender onde começaria a proteção dos direitos humanos nos seguintes termos:

Onde começam, afinal, os direitos humanos? Em pequenos locais, perto de casa - tão perto e tão pequenos que não podem ser vistos em quaisquer mapas do mundo. No entanto, são o mundo da pessoa individual, o bairro onde vive, a escola ou universidade que frequenta, a fábrica, ou escritório onde trabalha. Estes são os locais onde todos os homens, mulheres ou crianças procuram justiça social, oportunidade, dignidade sem discriminação. Se estes direitos não tiverem significado lá, terão pouco significado em qualquer outro lugar. Sem a ação do cidadão consciente, que os suporte perto de casa, será em vão que buscaremos o progresso neste vasto mundo (grifou-se).

\footnotetext{
${ }^{8}$ Sob a gestão da Organização dos Estados Americanos (OEA), o sistema interamericano de direitos humanos tem ganhado forças nas Américas, sobretudo, posteriormente à edição do Pacto de São José da Costa Rica, o qual tem colocado em discussão diversos dispositivos no âmbito legal e constitucional nos Estados americanos. Um exemplo é a Opinião Consultiva n. 5/1985, na qual a Corte Interamericana de Direitos Humanos (corte internacional que integra o sistema da OEA) manifestou-se contraria à obrigatoriedade do diploma e da inscrição em ordem profissional para o exercício da profissão de jornalista, o que, por sua vez, influenciou a decisão recente do Supremo Tribunal Federal brasileiro sobre o tema.

${ }^{9}$ O sistema regional africano de proteção dos direitos humanos desenvolveu-se na Organização de Unidade Africana (OUA), atual União Africana. $\bigcirc$ seu principal instrumento de direitos humanos é a Carta Africana dos Direitos do Homem e dos Povos de 1981 (DIREITOS HUMANOS).

${ }^{10}$ Importante salientar que a Corte Europeia de Direitos Humanos, também integrada dentro do sistema europeu de direitos humanos, tem julgado mais de mil casos ao ano (CLAPHAM, 2007, p. 52).
} 
Percebe-se, ao longo da história da proteção dos direitos humanos, uma proteção que acontece de forma coletiva, com vista ao que é ser humano de forma global, e não questões individuais. Todavia, quando se desconsideram determinadas individualidades, também se desprezam determinados grupos. Dessa forma, os sistemas de direitos humanos têm caminhado no sentido de reconhecer direitos de grupos mais individualizados, por exemplo, o direito das mulheres com a edição da Convenção da ONU sobre a Eliminação de todas as Formas de Discriminação Racial (1966); da Convenção Internacional para a Eliminação de todas as Formas de Discriminação Contra a Mulher ( 1979); e a Convenção Internacional sobre os Direitos da Criança ( 1989). Todavia, aponta-se para a continuidade da evolução dessa proteção no sentido de que se reconheçam direitos íntimos ao ser humano em específico, como a identidade, por exemplo.

\section{A PROTEÇÃO DA DIVERSIDADE NO CONTEXTO CONSTITUCIONAL BRASILEIRO E NA INTERPRETAÇÃO CONSTITUCIONAL}

Parece ter chegado o momento da discussão dos direitos humanos, seja no seu âmbito constitucional, global ou regional, de entender que há um supraprincípio tutelado, dimensão do princípio da dignidade humana, que é a proteção da diversidade.

A Constituição da República Federativa do Brasil não fala expressamente nessa proteção, mas procura a proteção efetiva da diversidade em muitas de suas passagens, uma vez que reafirma valores democráticos e estabelece como seu princípio fundamental a dignidade humana (art. $1^{\circ}$, III). Nesse sentido, entende-se que não pode haver o pressuposto de proteção da dignidade humana para uma figura hegemônica do que é ser humano, mas sim uma garantia dessa dignidade independentemente do ser humano a que se refira.

A Constituição também estabelece que são objetivos fundamentais da República Federativa do Brasil promover o bem de todos, sem preconceitos de origem, raça, sexo, cor, idade e quaisquer outras formas de discriminação (art. $3^{\circ}$, IV). Ou seja, os objetivos do País também constituem discurso que reconhece a diversidade e procura protegê-la.

No art. $5^{\circ}$ da Constituição Federal (CF), por sua vez, restam elementos que corroboram para que se conclua a existência de um princípio de proteção nesse sentido, pois estabelece que homens e mulheres são iguais em direitos e obrigações, bem como a criminalização e inafiançabilidade do racismo.

$\bigcirc$ art. 215 da Constituição Federal também suscita a importância de se proteger a diversidade, uma vez que prevê que o Estado deve garantir a todos o pleno exercício dos direitos culturais e acesso às fontes da cultura nacional, bem como o apoio e incentivo à valorização e à difusão das manifestações culturais.

Ademais, o art. 215 da Constituição Federal também profere que o Estado deve proteger as manifestações das culturas populares, indígenas e afro-brasileiras, e das de 
outros grupos participantes do processo civilizatório nacional, bem como a valorização da diversidade étnica e regional do País.

Nesse mesmo sentido, vale ressaltar que o art. 23I da Constituição Federal estabelece que são reconhecidos aos índios sua organização social, costumes, línguas, crenças e tradições, e os direitos originários sobre as terras que tradicionalmente ocupam, o que também, por sua vez, representa proteção de uma diversidade étnica existente na região.

Dessa forma, percebe-se que a Constituição Federal ao longo do seu texto procura proteger a diversidade sob suas mais diversas facetas: étnica, cultural e no âmbito dos gêneros.

Ademais, não se pode esquecer de que a Constituição Federal, desde seu preâmbulo, estabelece os valores democráticos como ponto de partida do Estado Brasileiro, o que corrobora ainda mais com o entendimento de que há abertura para esta diversidade articular-se.

A técnica da mutação constitucional " como forma de reinterpretação ${ }^{12}$ constitucional também se transformou num meio de lidar com a diversidade de uma democracia.

Embora alguns vejam a constituição como ordem hermeticamente fechada, essa visão parece não condizer mais com a realidade. Nesse sentido, Barroso (1996) posiciona-se:

uma das patologias crônicas da hermenêutica constitucional é a interpretação retrospectiva, pela qual se procura interpretar o texto novo de maneira a que ele não inove nada, mas, ao revés, fique tão parecido quanto o possível com o antigo (p. 73).

" O termo mutação constitucional tem origem na doutrina alemã e, buscando resgatar esse conceito, Uadi Lammêgo Bulos (2010, p. 23), define-a como: "... o processo informal de mudança da constituição, por meio do qual são atribuídos novos sentidos, conteúdos até então não ressaltados à letra da constituição, quer através da interpretação, em suas diversas modalidades e métodos, quer por intermédio da construção (construction), bem como dos usos e dos costumes constitucionais". No Brasil, Barroso (20 I0, p. I26- I27), por sua vez, afirma que: "... a mutação constitucional consiste em uma alteração do significado de determinada norma da constituição, sem observância do mecanismo constitucionalmente previsto para as emendas e, além disso, sem que tenha havido qualquer modificação de seu texto. Esse novo sentido ou alcance do mandamento constitucional pode decorrer de uma mudança na realidade fática ou de uma nova percepção do Direito, uma releitura do que deve ser considerado ético ou justo. Para que seja legítima, a mutação precisa ter lastro democrático, isto é, deve corresponder a uma demanda social efetiva por parte da coletividade, estando respaldada, portanto, pela soberania popular".

${ }^{12}$ Sistematizando, a partir da doutrina clássica, Barroso (20 I 0) procurou identificar os mecanismos de mutação constitucional, destacando-se: a interpretação (judicial e administrativa); a atuação do legislador; e a prática de costumes constitucionais. 
Percebe-se, portanto, que a Constituição deve ser sempre adaptada à realidade social, porque geralmente um discurso, por si só, não consegue dar conta da realidade jurídica construída e ampliada constantemente (SCHIER, 1997).

A técnica da mutação constitucional, que permite o texto positivado manter-se atualizado, diz respeito a um pressuposto de que a diversidade posteriormente surgida (ou reconhecida) precisa de proteção.

\title{
5 VALORES DEMOCRÁTICOS E O PRESSUPOSTO DE PROTEÇÃO DA DIVERSIDADE
}

\author{
Sobre democracia, Bobbio (2003) esclarece que
}

[...] a democracia é uma das três possíveis formas de governo na tipologia em que as várias formas de governo são classificadas com base no diverso número dos governantes. Em particular, é a forma de governo na qual o poder é exercido por todo o povo, ou pelo maior número, ou por muitos, e enquanto tal se distingue da monarquia e da aristocracia, nas quais o poder é exercido, respectivamente, por um ou por poucos (p. 137).

Ou seja, o próprio senso de pluralidade no exercício do poder dentro de um Estado Democrático de Direito, pressupõe um Estado que não deve proteger ou privilegiar determinado gênero, etnia ou classe social, mas as mais diversas facetas de gêneros, etnias e classes sociais (assim como outros grupos), os quais se inserem neste Estado, uma vez que em uma democracia o poder nunca permanece estagnado, passando simbolicamente nas mãos desSes diversos grupos (Leforte, 1990).

Nesse mesmo sentido, Robert Dahl (apud Habermas, 1997) alega que o processo democrático depende de cinco elementos para ser considerado legítimo, os quais são:
a) inclusão de todas as pessoas envolvidas;
b) chances reais de participação no processo político, repartidas equitativamente;
c) igual direito a voto nas decisões;
d) o mesmo direito para a escolha dos temas e para o controle da agenda; e) uma situação na qual todos os participantes, tendo à mão informações suficientes e bons argumentos, possam formar uma compreensão articulada acerca das matérias a serem regulamentadas e dos interesses controversos (p. 42).

Habermas (Ibid.) comenta que, até hoje, nenhuma ordem política conseguiu preencher suficientemente esses cinco critérios apresentados, mas ressalta que a complexidade social, que impede essa realização plena, não se opõe, em princípio, a uma implementação aproximativa do processo. Dessa forma, um princípio constitucional de proteção da diversidade seria pressuposto de um Estado democrático, sendo que tal 
garantiria que os Estados se aproximassem da própria democracia, porque garantiria a manutenção da sua pressuposta pluralidade de indivíduos.

Quanto às definições do que seria um Estado democrático, Rawls (1999) estipula uma lista de quais seriam os seus bens primários constitutivos nos seguintes termos:
a) Primeiro, as liberdades básicas tais como dadas por uma lista, por exemplo: liberdade de pensamento e liberdade de consciência; liberdade de associação. E a liberdade definida pela liberdade e integridade da pessoa, bem como pelo domínio (rule) da lei; e finalmente as liberdades políticas;
b) Segundo, liberdade de movimento e escolha de ocupação contra um fundo de oportunidades diversas;
c) Terceiro, poderes e prerrogativas de cargos e posições de responsabilidade, particularmente aquelas nas principais instituições políticas e econômicas;
d) Quarto, renda e riqueza; e
e) Finalmente, as bases sociais do autorrespeito (p. 326).

Dentre os elementos basilares citados por Rawls, entende-se que, sobretudo, a liberdade e o autorrespeito pressupõem a necessidade de as democracias protegerem a diversidade. A liberdade de ser quem se é e de estar inserido onde há identificação pressupõe uma sociedade diversa; e autorrespeito para com quem se é, independentemente de quem se seja, também pressupõe uma sociedade que tenha seu direito de se organizar de forma diversa.

\section{O DIREITO INTERNACIONALEA PROTEÇÃO DA DIVERSIDADE}

No âmbito internacional, por sua vez, é importante ressaltar que vários tratados internacionais tangenciam o princípio de proteção da diversidade. A Convenção sobre a Proteção e Promoção da Diversidade das Expressões Culturais, fruto da Conferência Geral da Organização das Nações Unidas para Educação; a Ciência e a Cultura, em sua $33^{a}$ reunião, celebrada em Paris, de 3 a 21 de outubro de 2005, por exemplo, afirma que a diversidade cultural é uma característica essencial da humanidade, constitui patrimônio comum dela, a ser valorizado e cultivado em benefício de todos, sabendo que a diversidade cultural cria um mundo rico e variado que aumenta a gama de possibilidades e nutre as capacidades e valores humanos, permitindo, assim, um dos principais motores do desenvolvimento sustentável das comunidades, povos e nações. Além disso, a referida convenção reconhece a necessidade de adotar medidas para proteger a diversidade das expressões culturais incluindo seus conteúdos, especialmente nas situações em que expressões culturais possam estar ameaçadas de extinção ou de grave deterioração.

No que se refere à orientação sexual e à identidade de gênero, ainda no âmbito internacional, a Comissão Internacional de Juristas e o Serviço Internacional de Direitos 
Humanos realizaram um projeto com o objetivo de desenvolver um conjunto de princípios jurídicos internacionais sobre a aplicação da legislação internacional às violações de direitos humanos, com base na orientação sexual e identidade de gênero, no sentido de dar mais clareza e coerência às obrigações de direitos humanos dos Estados. Sendo assim, depois de uma reunião de especialistas, realizada na Universidade Gadjah Mada, em Yogyakarta, Indonésia, entre 6 e 9 de novembro de 2006, 29 especialistas de 25 países, com experiências diversas e conhecimento relevante das questões da legislação de direitos humanos, adotaram, por unanimidade, os Princípios de Yogyakarta ${ }^{13}$ sobre a Aplicação da Legislação Internacional de Direitos Humanos em relação à Orientação Sexual e Identidade de Gênero.

\footnotetext{
${ }^{13}$ Os princípios elencados no referido documento são os seguintes: PRINCÍPIO I Direito ao Gozo Universal dos Direitos Humanos; PRINCÍPIO 2. Direito à lgualdade e à Não Discriminação; PRINCÍPIO 3. Direito ao Reconhecimento Perante a Lei; PRINCÍPIO 4. Direito à Vida; PRINCÍPIO 5. Direito à Segurança Pessoal; PRINCÍPIO 6. Direito à Privacidade; PRINCÍPIO 7. Direito de Não Sofrer Privação Arbitrária da Liberdade; PRINCÍPIO 8. Direito a um Julgamento Justo; PRINCÍPIO 9. Direito a Tratamento Humano durante a Detenção; PRINCÍPIO I0. Direito de Não Sofrer Tortura e Tratamento ou Castigo Cruel, Desumano e Degradante;

PRINCÍPIO I I. Direito à Proteção Contra todas as Formas de Exploração, Venda ou Tráfico de Seres Humanos;

PRINCÍPIO 12. Direito ao Trabalho;

PRINCÍPIO I3. Direito à Seguridade Social e outras Medidas de Proteção Social;

PRINCÍPIO I 4. Direito a um Padrão de Vida Adequado;

PRINCÍPIO I 5. Direito à Habitação Adequada;

PRINCÍPIO 16. Direito à Educação;

PRINCÍPIO 17. Direito ao Padrão mais Alto Alcançável de Saúde;

PRINCÍPIO I 8. Proteção contra Abusos Médicos;

PRINCÍPIO 19. Direito à Liberdade de Opinião e Expressão;

PRINCÍPIO 20. Direito à Liberdade de Reunião e Associação Pacíficas;

PRINCÍPIO 21 . Direito à Liberdade de Pensamento, Consciência e Religião;

PRINCÍPIO 22. Direito à Liberdade de Ir e Vir;

PRINCÍPIO 23. Direito de Buscar Asilo;

PRINCÍPIO 24. Direito de Constituir uma Família;

PRINCÍPIO 25. Direito de Participar da Vida Pública;

PRINCÍPIO 26. Direito de Participar da Vida Cultural;

PRINCÍPIO 27. Direito de Promover os Direitos Humanos;

PRINCÍPIO 28. Direito a Recursos Jurídicos e Medidas Corretivas Eficazes;

PRNCÍPIO 29. Responsabilização (“Accountability”).
} 
Os Princípios de Yogyakarta tratam de um amplo espectro de normas de direitos humanos e de sua aplicação a questões de orientação sexual e identidade de gênero. Esses princípios afirmam a obrigação primária de os Estados implementarem os direitos humanos. Cada princípio é acompanhado de detalhadas recomendações aos Estados. No entanto, o texto do documento também enfatiza que muitos outros atores têm responsabilidades na promoção e proteção dos direitos humanos, incluindo-se, assim, o sistema de direitos humanos das Nações Unidas, instituições nacionais de direitos humanos, mídia, organizações não governamentais e financiadores; responsabilização que permite até mesmo concluir que o princípio da proteção da diversidade depende de uma gestão compartilhada de diversos atores, bem como concluir que proteger a diversidade pressupõe também promovê-la.

A Convenção sobre a Eliminação de todas as Formas de Discriminação contra a Mulher, de 1979, por suavez, reconhece que

\begin{abstract}
a discriminação contra a mulher viola os princípios da igualdade de direitos e do respeito da dignidade humana, dificulta a participação da mulher, nas mesmas condições que o homem, na vida política, social, econômica e cultural de seu país, constitui um obstáculo ao aumento do bem-estar da sociedade e da família e dificulta o pleno desenvolvimento das potencialidades da mulher para prestar serviço a seu país e à humanidade.
\end{abstract}

Diante disso, a referida convenção aponta para medidas necessárias a serem adotadas pelos Estados, a fim de suprimir essa discriminação em todas as suas formas e manifestações. Dentre tais medidas, ressaltam-se: inscrever na sua constituição nacional ou em qualquer outra lei apropriada o princípio da igualdade dos homens e das mulheres e assegurar por via legislativa ou por outros meios apropriados a aplicação efetiva do mesmo princípio; adotar medidas legislativas e outras medidas apropriadas, incluindo a determinação de sanções em caso de discriminação; tomar medidas apropriadas para eliminar a discriminação praticada contra as mulheres por uma pessoa, uma organização ou uma empresa qualquer; tomar todas as medidas apropriadas, incluindo disposições legislativas, para modificar ou revogar qualquer lei, disposição regulamentar, costume ou prática que constitua discriminação contra as mulheres; revogar todas as disposições penais que constituam discriminação contra as mulheres; modificar os esquemas e modelos de comportamento socioculturais dos homens e das mulheres com vista a alcançar a eliminação dos preconceitos e das práticas costumeiras, ou de qualquer outro tipo, que se fundem na ideia de inferioridade ou de superioridade de um ou de outro gênero ou de um papel estereotipado dos homens e das mulheres; assegurar que a educação familiar contribua para um entendimento correto da maternidade como função social e para o reconhecimento da responsabilidade comum dos homens e das mulheres na educação e desenvolvimento dos filhos. 
Ademais, a Convenção sobre a Eliminação de todas as Formas de Discriminação contra a Mulher, de 1979, exige dos Estados o reconhecimento dos seguintes direitos: de votar em todas as eleições e em todos os referendos públicos e de serem elegíveis para todos os organismos publicamente eleitos; de tomar parte na formulação da política do Estado e na sua execução, de ocupar empregos públicos e de exercer todos os cargos públicos a todos os níveis do governo; de participar nas organizações e associações não governamentais que se ocupem da vida pública e política do País.

Nesse sentido, é importante salientar que a Constituição da República Federativa do Brasil, de 1988, já fora formatada em consonância com a Convenção sobre a Eliminação de todas as Formas de Discriminação contra a Mulher, de 1979. Sobre este assunto, cumpre ressaltar que

Assim se formou no Congresso Constituinte uma aliança suprapartidária que levantou bandeiras que viriam a ser bemsucedidas como a licença-maternidade de 120 dias (art. $7^{\circ}$, XVIII), o direito ao título de domínio de terra à mulher (art. 194), a igualdade de salários entre homem e a mulher (art. $7^{\circ}$, $X X X)$, além de garantir a igualdade de direitos (art. $5^{\circ}$, caput) e, pela primeira vez na história constitucional do país, lançar mão de ações afirmativas na busca da igualdade material, bem de acordo com o Estado Democrático e Social delineado na Constituição de 1988 (BERTOLIN; SÁLVIA, 2015, p. 99-100).

Cumpre ressaltar que, com o mesmo intuito, foi editada a Lei $n^{\circ}$ | I.340, de 7 de agosto de 2006, popularmente conhecida como Lei Maria da Penha, configurando verdadeiro marco na história legislativa brasileira, pois se procurou punir, de modo mais severo e célere, a violência que ocorre no âmbito familiar, contra a mulher. (BARUKI; BERTOLIN, 20|0).

Além das questões de gênero e cultura, a comunidade internacional, por meio da edição da Convenção de Nova York sobre os Direitos das Pessoas com Deficiência ${ }^{14}$, de 2006, desenvolveu um conceito de deficiência pautado implicitamente no princípio da proteção da diversidade, procurando discutir a questão sob o ponto de vista da articulação de seres humanos minoritários com uma sociedade regida e pensada por (e para) uma maioria diferente dessas minorias, chamando a atenção para a pluralidade de indivíduos que existe dentro da terminologia pessoas com deficiência.

${ }^{14}$ Em 2008, o Brasil internalizou a Convenção sobre os Direitos das Pessoas com Deficiência: o primeiro tratado de Direitos Humanos recepcionado com status equivalente a emenda constitucional. É importante também recordar que no país há cerca de 45 milhões de brasileiros e brasileiras com deficiência (NOVOS COMENTÁRIOS À CONVENÇÃO DA PESSOA COM DEFICIÊNCIA, 20|4). 
Nesse sentido, vale ressaltar que no preâmbulo da referida convenção reconhecese: que a discriminação contra qualquer pessoa, por motivo de deficiência, configura violação da dignidade e do valor inerentes ao ser humano; a diversidade das pessoas com deficiência; a importância da cooperação internacional para melhorar as condições de vida das pessoas com deficiência em todos os países, particularmente naqueles em desenvolvimento; as difíceis situações enfrentadas por pessoas com deficiência que estão sujeitas a formas múltiplas ou agravadas de discriminação por causa de raça, cor, sexo, idioma, religião, opiniões políticas ou de outra natureza, origem nacional, étnica, nativa ou social, propriedade, nascimento, idade ou outra condição; que mulheres e meninas com deficiência estão frequentemente expostas a maiores riscos, tanto no lar como fora dele, de sofrer violência, lesões ou abuso, descaso ou tratamento negligente, maus-tratos ou exploração; a necessidade de incorporar a perspectiva de gênero aos esforços para promover o pleno exercício dos direitos humanos e liberdades fundamentais por parte das pessoas com deficiência.

Ademais, vale ressaltar que a referida convenção, de acordo com seu art. $3^{\circ}$, rege-se pelos seguintes princípios: o respeito pela dignidade inerente, a autonomia individual, até mesmo a liberdade de fazer as próprias escolhas, e a independência das pessoas; a não discriminação; a plena e efetiva participação e inclusão na sociedade; o respeito pela diferença e pela aceitação das pessoas com deficiência como parte da diversidade humana e da humanidade; a igualdade de oportunidades; a acessibilidade; a igualdade entre o homem e a mulher; o respeito pelo desenvolvimento das capacidades das crianças com deficiência e pelo direito de as crianças com deficiência preservarem sua identidade.

Ainda sobre a questão da deficiência, vale ressaltar que a perspectiva feminista tem qualificado o debate sobre o corpo no contexto dos estudos sobre deficiência, especialmente no tocante à radicalização do pressuposto da desnaturalização do corpo (MELLO; NUERBENG; 20 I 2). Nesse sentido, conforme Garland-Thomson (2009), as teorias feministas levam esse debate para além da crítica ao corpo perfeito e às barreiras de acesso, à medida que contemplam uma análise profunda sobre o estatuto social e cultural do corpo, sobre a política da aparência, a medicalização do corpo e da subjetividade e a construção social da identidade no contexto do corpo considerado deficiente.

Sendo assim, percebe-se que esses debates sobre o corpo corroboram para que se entenda o que alicerça a proteção da diversidade, porque ela não pressupõe uma proteção de algo que seja inferior ou necessariamente mais frágil. Pelo contrário, a proteção da diversidade reconhece que o diverso não é menos referencial que o hegemônico nem necessariamente mais frágil ou, de fato, deficiente. Ou seja, em alguns momentos, proteger diversidade significa imputar responsabilidade sobre o diverso, negar sua fragilidade e abdicar da superproteção.

Dessa forma, parece que o Estatuto da Pessoa com Deficiência (Lei n ${ }^{1}$ 3. I 46, de 6 de julho de 20 15), inspirado na Convenção de Nova York sobre os Direitos das Pessoas com Deficiência, de 2006, absorveu esse entendimento e revogou as hipóteses de 
incapacidade absoluta do Código Civil, de 2002, por meio de seu art. $3^{\circ}$, mantendo somente a hipótese de menores de 16 anos serem considerados absolutamente incapazes.

Nesse mesmo sentido, foi editado o Tratado de Marraqueche para facilitar o acesso às obras publicadas às pessoas cegas, com deficiência visual ou com outras dificuldades para aceder ao texto impresso ${ }^{15}$, de 27 de junho de 2013 , sendo importante salientar que o acesso à cultura por parte das pessoas cegas não é somente importante para lhes conferir igualdades de oportunidades, mas também para que haja uma maior troca entre cegos e não cegos, porque, com certeza, diferentes experiências corroboram umas com as outras.

A partir de textos mais amplos sobre a temática dos direitos humanos também é possível verificar que estes foram redigidos com vista a proteger a diversidade. A Declaração Universal de Direitos Humanos, por exemplo, em seu art. $1^{\circ}$, estabelece que "todos os seres humanos nascem livres e iguais em dignidade e em direitos". Pautada neste artigo, a Organização das Nações Unidas desenvolveu a campanha Livres e lguais, a qual, por sua vez, procura promover a igualdade de lésbicas, gays, bissexuais, travestis e transexuais (LGBT), e um maior respeito pelos direitos das pessoas LGBT, em todos os lugares do mundo (NASCIDOS LIVRES E IGUAIS; 20I3).

Dessa forma, a campanha Livres e lguais recomenda aos Estados que tomem as seguintes providências:

I. Proteger as pessoas da violência homofóbica e transfóbica. Incluir a orientação sexual e a identidade de gênero como características protegidas por leis criminais contra o ódio. Estabelecer sistemas efetivos para registrar e relatar atos de violência motivados pelo ódio. Assegurar investigação efetiva, instauração de processo contra os perpetradores e reparação das vítimas de tal violência. Leis e políticas de asilo devem reconhecer que a perseguição de alguém com base em sua orientação sexual ou identidade de gênero pode ser um motivo válido para um pedido de asilo;

2. Prevenir a tortura e o tratamento cruel, desumano e degradante às pessoas LGBT em detenção através da proibição e punição de tais atos, garantindo que as vítimas sejam socorridas. Investigar todos os atos de maus tratos por agentes

${ }^{15}$ Ratificado por 20 países, o Tratado foi assinado durante reunião da Organização Mundial da Propriedade Intelectual (OMPI), em Marraqueche, Marrocos. A proposta do texto foi de autoria do Brasil, em parceria com Paraguai e Equador. Importante também apontar que o Tratado de Marraqueche, assim como a Convenção de Nova York sobre os Direitos das Pessoas com Deficiência, foi incorporado ao ordenamento jurídico brasileiro com status emenda constitucional. 
do Estado e levar os responsáveis à justiça. Prover treinamento apropriado aos funcionários responsáveis pela aplicação da lei e garantir um controle eficaz dos locais de detenção;

3. Revogar leis que criminalizam a homossexualidade, incluindo todas as leis que proíbem a conduta sexual privada entre adultos do mesmo sexo. Assegurar que não sejam presos ou detidos em razão de sua orientação sexual ou identidade de gênero, e não sejam submetidos a exames físicos degradantes e desnecessários com a finalidade de determinar sua orientação sexual;

4. Proibir a discriminação com base na orientação sexual e identidade de gênero. Promulgar leis abrangentes que incluam a orientação sexual e identidade de gênero como motivos proibidos para discriminação. Em especial, assegurar o acesso não discriminatório a serviços básicos, inclusive nos contextos de emprego e assistência médica. Prover educação e treinamento para prevenir a discriminação e estigmatização de pessoas intersexo e LGBT;

5. Proteger as liberdades de expressão, de associação e de reunião pacífica para as pessoas intersexo e LBGT. Qualquer limitação destes direitos deve ser compatível com o direito internacional e não deve ser discriminatória. Proteger indivíduos que exercitam seus direitos de liberdade de expressão, de associação e de reunião dos atos de violência e intimidação por grupos privados (NASCIDOS LIVRES E IGUAIS, 2013, p. 13).

Nesse mesmo sentido, ainda no que diz respeito ao sistema global de proteção dos direitos humanos, vale lembrar que o art. 27 do Pacto Internacional sobre os Direitos Civis e Políticos dispõe sobre os direitos das pessoas pertencentes a minorias étnicas, religiosas e linguísticas; o que, por sua vez, pressupõe obviamente proteção da diversidade. Foi até mesmo pautado, neste artigo, em que se elaborou a Declaração sobre os Direitos das Pessoas Pertencentes a Minorias Nacionais ou Étnicas, Religiosas e Linguísticas, a qual procura assegurar a aplicação ainda mais efetiva dos instrumentos internacionais de direitos humanos no que diz respeito aos direitos das pessoas pertencentes a estas minorias.

No âmbito do sistema interamericano de direitos humanos, por sua vez, cumpre ressaltar que a Convenção Americana de Direitos Humanos reafirma seu propósito de consolidar nas Américas, dentro do quadro das instituições democráticas, um regime de liberdade pessoal e de justiça social, fundado no respeito dos direitos essenciais.

Sendo assim, vale destacar que, para Nancy Fraser (200 I), a justiça social exige, simultaneamente, redistribuição e reconhecimento de identidades nos seguintes termos: 
O reconhecimento não pode se reduzir à distribuição, porque o status na sociedade não decorre simplesmente em função da classe. Tomemos o exemplo de um banqueiro afro-americano de Wall Street, que não consegue tomar um taxi. Neste caso, a injustiça da falta de reconhecimento tem pouco a ver com a má distribuição. (...) Proponho desenvolver o que chamo concepção bidimensional da justiça. Esta concepção trata da redistribuição e do reconhecimento como perspectivas e dimensões distintas da justiça. Sem reduzir uma a outra, abarca ambas em um marco mais amplo (p. 55-56).

Ou seja, o conceito de justiça social reafirmado pela Convenção Americana de Direitos Humanos pressupõe a proteção de uma diversidade de indivíduos que precisam ser reconhecidos e afirmados. Nesse mesmo sentido, o art. $8^{\circ}$ da referida Convenção estabelece que "toda pessoa tem o direito de que se respeite sua integridade física, psíquica e moral"; o que corrobora com o entendimento de que é necessário proteger os indivíduos tais como eles são.

\section{CONSIDERAÇÕES FINAIS}

Percebe-se que a valorização do ser humano e o reconhecimento que sua existência digna necessita de que direitos mínimos sejam reconhecidos faz parte da história da vida humana.

Percebe-se também que a evolução desse reconhecimento dá-se até alcançar-se uma sistemática internacional de proteção de direitos humanos e uma proteção constitucional desses direitos.

É importante discutir onde começam os direitos humanos para se traçarem os próximos caminhos no que se refere à tutela desses direitos, porque é nesse embrião de proteção que se deve focar.

Sendo assim, parece que a proteção dos direitos humanos deve-se voltar, daqui para frente, seguindo a sua evolução, para o que Roosevelt chamou de mundo individual da pessoa.

Percebe-se, portanto, que proteger a diversidade é responsabilidade: constitucional e dos Estados; dos sistemas internacionais de proteção dos direitos humanos e da comunidade internacional; bem como dos próprios sistemas democráticos e da sociedade civil.

Sendo assim, é importante tornar visível esse princípio para que seja possível articular uma sistemática protetiva da diversidade como próximo passo a ser dado no que diz respeito ao processo evolutivo de proteção dos direitos humanos. Dessa forma, é importante salientar que a doutrina, jurisprudência, textos normativos (constitucionais, infraconstitucionais e internacionais) versem expressamente sobre esse princípio e comecem a regular a articulação dessa sistemática. 
Por meio da articulação de uma sistemática de proteção da diversidade é possível alocar leis, tratados, dispositivos constitucionais e convenções, dispersos no universo jurídico, e agrupá-los dentro desse sistema. Sendo assim, fica mais didático localizar tais textos, bem como identificar quais direitos inerentes à proteção da diversidade carecem de regulamentação.

\section{REFERÊNCIAS}

ARENDT, Hannah. As origens do totalitarismo. São Paulo: Companhia das Letras, 1989.

ARRUDA, José Jobson de A. História antiga e medieval. São Paulo: Ática, 1995.

BAGNOLI, Vicente. Direito e Poder Econômico. São Paulo: Atlas, 2005.

BALTES, Paul. On the incomplete architecture of human ontogeny: Selection, optimization, and compensation as foundation of developmental theory. Disponível em: <http://psycnet.apa.org/index.cfm?fa=buy.optionToBuy\&uid = 1997-03698-009>. Aceso em 8 jan. 2017.

BARROSO, Luís Roberto. Natureza jurídica e funções das Agências Reguladoras de serviços públicos. In: Boletim de direito administrativo. Ano XV, n. 6, junho/I 999.

O direito constitucional e a efetividade de suas normas: limites e possibilidades da Constituição Brasileira. Rio de Janeiro: Renovar, 1996.

BARUKI, Luciana Veloso Rocha Portolese; BERTOLIN, Patrícia Tuma Martins. Violência contra mulher: a face mais perversa do patriarcado. Quem tem medo de lobo mau? In: BERTOLIN, Patrícia Tuma Martins; ANDREUCCl, Ana Claudia Pompeu Torezan. Mulher, Sociedade e Direitos Humanos. São Paulo: Rideel, 2010.

BERTOLIN, Patrícia Tuma Martins; SALVIA, Stéphanie G. de Carvalho. A violência em face da mulher no Estado democrático de direito brasileiro: a efetivação do Programa 'Mulher, viver sem violência'. Revista Paradigma, v. 24, p. 97-1 19, 2015. Disponível em: <file:///C:/Users/Sony/Dropbox/Doutorado/Bibliografia/572-207I-3-PB.pdf>. Acesso em 27 mar. 2017.

BOBBIO, Norberto. A era dos direitos. Rio de janeiro: Campus, 1992. 
BRASIL. Lei n. II.340, de 7 de agosto de 2006. Disponível em: < http://www.planalto.gov.br/ccivil_03/_ato2004-2006/2006/lei/l I 340.htm>. Acesso em 27 mar. 2017.

CANTU, Césare. História universal. V. I. São Paulo: Américas, 2003.

CLAPHAM, Andrew. Human Rights: a very short introduction. New York: Oxford, 2007.

COMPARATO, Fábio Konder. A Afirmação Histórica dos Direitos Humanos. 3. ed. São Paulo: Saraiva, 2003.

CONSTITUIÇÃ O FEDERAL. Disponível e m : $<$ http://www.planalto.gov.br/ccivil_03/constituicao/constituicao.htm>. Acesso em 4 mar. 2017.

CONVENÇÃO SOBRE A ELIMINAÇÃO DE TODAS AS FORMAS DE DISCRIMINAÇÃO CONTRA A MULHER. Disponível em: < http://www.pge.sp.gov.br/centrodeestudos/bibliotecavirtual/instrumentos/discrimulhe r.htm>. Acesso em 14 mar. 2017.

CONVENÇÃO SOBRE A PROTEÇÃO E A PROMOÇÃO DA DIVERSIDADE DAS EXPRESSÕES CULTURAIS. Disponível em: <http://www.ibermuseus.org/wpcontent/uploads/20 | 4/07/convencao-sobre-a-diversidade-das-expressoes-culturaisunesco-2005.pdf>. Acesso em 14 mar. 2017.

CONVENÇÃO SOBRE OS DIREITOS DAS PESSOAS COM DEFICIÊNCIA. Disponível em: <http://www.planalto.gov.br/ccivil_03/_ato20072010/2009/decreto/d6949.htm >. Acesso em 19 mar. 2017.

COSTA, P. T. Jr.; MCCRAE, R. R. Set like plaster? Evidence for the stability of adult personality. In: HEATHERTON, T. F. \& WEINBERGER, J. L. Can personality change? Washington, DC: American Psychological Association, 1994.

DA SILVA, Luiza Gomes. A evolução dos direitos humanos. Disponível em: < http://www.conteudojuridico.com.br/artigo,a-evolucao-dos-direitoshumanos,42785.html\#_ftn 187> Acesso em 29 dez. 2016. 
DIAS; Joelson; FERREIRA, Laíssa da Costa; GUGEL, Maria Aparecida; COSTA FILHO; Waldir Macieira (Org.). Novos comentários à convenção da pessoa com deficiência. Brasília: Secretaria de Direitos Humanos da Presidência da República, 20 I 4. Disponível e $\mathrm{m}$ :

http://www.pessoacomdeficiencia.gov.br/app/sites/default/files/publicacoes/convenca o-sdpcd-novos-comentarios.pdf>. Acesso em 19 mar. 2017.

DIREITO INTERNACIONAL. Legislação. Pacto Internacional dos Direitos Civis e Políticos, de 16 de dezembro de 1966. Disponível em: <http://www.rolim.com.br/2002/_pdfs/067.pdf>. Acesso em I ${ }^{\circ}$ out. 2016.

DIREITO INTERNACIONAL. Legislação. Pacto Internacional sobre Direitos Econômicos, Sociais e Culturais, de 1976. Disponível em: <http://www2.mre.gov.br/dai/m_59|_1992.htm>. Acesso em I ${ }^{\circ}$ out. 2016.

. Legislação. Declaração Universal dos Direitos Humanos. Disponível em: <http://www.ohchr.org/EN/UDHR/Documents/UDHR_Translations/por.pdf>. Acesso em 27 mar. 2017.

- Legislação. Pacto Internacional dos Direitos Civis e Políticos, de 16 de $\overline{\mathrm{dez}} \mathrm{e}$ mbro de $\quad$ i 966 . Disponível e m : <http://www.rolim.com.br/2002/_pdfs/067.pdf>. Acesso em I out. 2016.

Limonad, 1996.

Direitos humanos e o direito constitucional internacional. São Paulo: Max - Direitos humanos: o princípio da dignidade humana e a Constituição brasileira de 1988. In: Revista dos Tribunais, ano 94. v. 833, p. 4I -53. São Paulo: RT, mar. 2005.

- Legislação. Convenção Americana de Direitos Humanos. Disponível em: $<$ https://www.cidh.oas.org/basicos/portugues/c.convencao_americana.htm > . Acesso em 27 mar. 2017.

- Legislação. Pacto Internacional sobre Direitos Econômicos, Sociais e Culturais, de 1976. Disponível em: <http://www2.mre.gov.br/dai/m_59|_| 992.htm > . Acesso em $1{ }^{\circ}$ out. 2016.

- Legislação. Convenção sobre os Direitos da Criança. Disponível em:

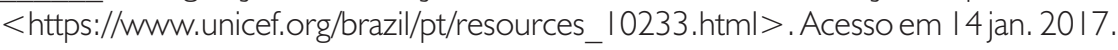


- Legislação. Convenção sobre os Direitos da Criança. Disponível em:

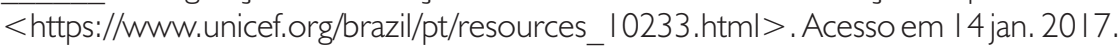

- Legislação. Convention on the Prevention and Punishment of the Crime of Genocide. Dis pon ível e m : $<$ http://www.ohchr.org/EN/Professionallnterest/Pages/CrimeOfGenocide.aspx>. Acesso em 29 jan. 2017.

- Legislação. Declaração sobre os Direitos das Pessoas Pertencentes a Minorias Nacionais ou Étnicas, Religiosas e Linguísticas. Disponível em: <http://direitoshumanos.gddc.pt/3_2/IIIPAG3_2_I0.htm>. Acesso em 27 mar. 2017.

. Legislação. Rome statute of the international criminal court. Disponível em:

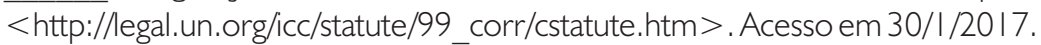

D I REITOS HUMANOS. Disponível e m : <http://direitoshumanos.gddc.pt/2_3/IIPAG2_3.htm>. Acesso em 6 jan. 2017.

DONNELLY, Jack. What are human rights?: An Historical and Conceptual Analysis. 1981. 469 f. Tese (Doutorado em Filosofia Política). Berkeley: University of California, |981.

DUARTE, Clarice Seixas. O ciclo de políticas públicas. In: SMANIO, Gianpaolo Poggio; BERTOLIN, Patrícia Tuma Martins (Org.). O direito e as políticas públicas. São Paulo: Atlas, 2014.

ESTATUTO DA PESSOA COM DEFICIÊNCIA. Disponível em: < http://www.planalto.gov.br/ccivil_03/_ato20 I5-20 I8/20 I 5/lei/l I | 46.htm>. Acesso em 27 mar. 2017.

FERREIRA FILHO, Manoel Gonçalves. Aspectos do Direito Constitucional Contemporâneo. São Paulo: Saraiva, 2003.

FINNIS, John. Lei Natural E Direitos Naturais (Tradução de Leila Mendes). São Leopoldo: Editora Unisinos, 2007.

GRAU, Eros Roberto. A Ordem Econômica na Constituição de 1988. 15. ed. São Paulo: Malheiros, 2010. 
HABERMAS, Jürgen. Direito e democracia: entre facticidade e norma. Trad. Flávio Sibeneichler. Rio de Janeiro: Tempo Brasileiro, 1997.

LALAGUNA, Paloma Durán. Manual de Derechos Humanos. Granada: Comares, 1993.

LEFORT, Claude. La invención democrática. Buenos Aires, Argentina: Ediciones Nueva Visión, 1990.

MARTINS, Flademir Jerônimo Belinati. Dignidade da Pessoa Humana: Princípio Constitucional Fundamental. Curitiba: Juruá Editora, 2003.

MELLO, Anahi Guedes; NUERNBERG, Adriano Henrique. Gênero e deficiência: interseções e perspectivas. In: Revista de Estudos Feministas. vol.20, n.3, Florianópolis, sept./dec. 2012.

MORAES, Alexandre de. Direitos humanos fundamentais: teoria geral (comentários aos artigos $1^{\circ}$ a $5^{\circ}$ da Constituição da República Federativa do Brasil - doutrina e jurisprudência. Coleção Temas Jurídicos, v. 3, 3. ed. São Paulo: Atlas, 2000.

NASCIDOS LIVRES E I GUAIS. Disponível e m: $<$ https://nacoesunidas.org/img/2013/03/nascidos_livres_e_iguais.pdf $>$. Acesso em 27 mar. 2017.

PARDO MONTANO, Ana Melisa. Migración internacional y desarrollo. Aportes desde el transnacionalismo. In: Revista de Estudios Sociales, Edición n. 54, p. 39-5 I, oct-dic 2015.

PATRICIO, Maria Cecília. O travesti: uma questão de gênero. Mestrado (Antropologia). Recife: UNIVERSIDADE, 2002.

PINSKY, Jaime. Os Profetas Sociais e o Deus da Cidadania. In: PINSKY, Jaime, PINSKY, Carla Bassanezi (org.). História da Cidadania. São Paulo: Contexto, 2003.

PIOVESAN, Flávia. Cidadania global é possível? In: PINSKY, Jaime (org). Práticas de cidadania. São Paulo: Contexto, 2004.

PRINCIPIOS DE YOGYAKARTA. Disponível e m: $<$ http://mww.clam.org.br/uploads/conteudo/principios_de_yogyakarta.pdf $>$. Acesso em 14 mar. 2017. 
PSICOATIVO. Id, ego e superego. Disponível em: $<$ http://psicoativo.com/20 l 6/05/resumo-id-ego-e-superego.html>. Acesso em 8 jan. 2017.

RAWLS, John. Collected papers. London: Harvard University Press, 1999.

ROBERTS, Brent; CASPI, Avshalom. The cumulative continuity model of personality development: Striking a balance between continuity and change in personality traits across the life course. In: STAUDINGER, Ursula; LINDENBERGER, Ulman. (Org.) Understanding human development: Life span psychology in exchange with other disciplines (p. | 83-2 | 4). Dodrecht: Kluwer, 2003.

ROUGHGARDEN, Joan. The gender binary in nature, across human cultures, and in the bible. In: SCHREIBER, Gerhad. Transsexualität in theologie und neurowissenschaften. Walter: De Gruyter, 2016.

RUBIO, Valle Labrada. Introduccion a la Teoria de los Derechos Humanos: Fundamento. Historia. Declaracion Universal de 10 de diciembre de 1948. Madrid: Civitas, 1998.

SMANIO, Gianpaolo Poggio. Legitimidade jurídica das políticas públicas: a efetivação da cidadania. In: SMANIO, Gianpaolo Poggio; BERTOLIN, Patrícia Tuma Martins (Org.). O direito e as políticas públicas. São Paulo: Atlas, 2014.

. Dimensões da cidadania. In: Novos Direitos e Proteção da Cidadania - Revista Jurídica da Escola Superior do Ministério Público. Ano 2 - janeiro/junho 2009.

SODER, José. Direitos do homem. São Paulo: Companhia Editorial Nacional, 1960.

UNESCO, Brasil. Convenção da ONU sobre a Eliminação de todas as Formas de D i s criminação Racial ( 1966 ). Disponível e m : <http://unesdoc.unesco.org/images/00 I3/00 I393//39390por.pdf>. Acesso em I4 jan. 2017.

UNICEF Brasil. Convenção sobre a Eliminação de Todas as Formas de Discriminação Contra as Mulheres ( 1979 ). Disponível e m: $<$ https://www.unicef.org/brazil/pt/resources_I 0233.html>. Acesso em I 4 jan. 2017.

Recebido em: 31/05/2017

Aprovado em: 16/06/2017 
